\title{
Long non-coding RNA AK055347 is upregulated in patients with atrial fibrillation and regulates mitochondrial energy production in myocardiocytes
}

\author{
GUIYING CHEN*, HONG GUO*, YING SONG, HUIYING CHANG, \\ SHAOJUN WANG, MIAOMIAO ZHANG and CHANG LIU
}

Department of Cardiology, The First Affiliated Hospital of Harbin Medical University, Harbin, Heilongjiang 150001, P.R. China

Received September 10, 2015; Accepted September 22, 2016

DOI: $10.3892 / \mathrm{mmr} .2016 .5893$

\begin{abstract}
The role of long non-coding RNAs (lncRNAs) in atrial fibrillation remains to be fully elucidated. The current study performed microarray analysis to investigate differential lncRNA expression profiling in atrial samples from the pulmonary vein and the surrounding left atrial area (LA-PV) and from the left atrial appendage (LAA) in 16 patients with atrial fibrillation (AF). Microarray analysis identified 94 lncRNAs that were differentially expressed between the LA-PV and LAA in patients with AF. AK055347 was one of lncRNAs with the most significant alterations observed. Knockdown of AK055347 inhibited cell viability of H9C2 cardiomyocytes, accompanied by downregulation of Cyp450 and ATP synthases. In addition, microarray analysis identified that MSS51 was a target of AK055347. Knockdown of AK055347 inhibited the expression of MSS51 in H9C2 cells. The observations of the current study suggest that lncRNAs are differentially expressed in the LA-PV and LAA in patients with AF. AK055347 may contribute to the pathogenesis of AF by dysregulating mitochondrial energy production via regulation of Cyp450, ATP synthase and MSS51.
\end{abstract}

\section{Introduction}

Atrial fibrillation (AF) is a common cardiac arrhythmia, characterized as an irregular and rapid heart rate. AF has been identified to be associated with ischemic stroke, hypertension, and heart failure (1-3). The incidence of AF increases with increasing age (4), and with the increasing population of elderly patients, AF is predicted to cause increased morbidity

Correspondence to: Dr Ying Song, Department of Cardiology, The First Affiliated Hospital of Harbin Medical University, 23 Youzheng Street, Nangang, Harbin, Heilongjiang 150001, P.R. China

E-mail: songying_2015@sina.com

*Contributed equally

Key words: atrial fibrillation, microarray, long non-coding RNA, lncRNAs, AK055347, MSS51 and mortality. However, the etiology of AF is complex and unclear, and inherited and environmental factors have been reported to be involved $(5,6)$.

The progression of AF is commonly accompanied with alterations in gene expression, thus resulting in abnormal protein expression expression (7,8). A previous study identified that long non-coding RNAs (lncRNAs), endogenous RNAs >200 nucleotides in length that do not code for functional proteins, regulate the gene expression of numerous proteins (9). Several studies have demonstrated that lncRNAs are associated with diseases including cancer (10), endocrine diseases (11), liver diseases (12) and heart diseases $(13,14)$. IncRNAs are important in the regulation of cardiogenesis (14) and associated with numerous cardiac diseases such as myocardial infarction (15), heart failure (16) and left ventricular hypertrophy (17). However, the association between lncRNAs and AF has not been explored yet.

Previous studies have demonstrated that AF is associated with a higher demand of energy in cardiomyocytes $(18,19)$. Additional studies have demonstrated that AF is associated with impaired energy synthesis or consumption (20-22). Therefore, alterations in the energy metabolism may contribute to the pathogenesis of AF (22). IncRNAs have been observed to serve a role in the energy metabolism in brown adipose tissues (23). It remains unclear whether lncRNAs are involved in energy metabolism in cardiomyocytes.

It has been reported that compared with the left atrial appendage (LAA), the pulmonary vein and the surrounding left atrial area (LA-PV) exhibited with 391 differentially expressed genes that included genes associated with arrhythmia cell death and inflammation, suggesting that region-specific gene expression may contribute to AF pathogenesis (8). In the present study, microarray analysis was conducted to investigate the differential lncRNA expression profiling in atrial samples from the LA-PV and from the LAA in patients with AF. The purpose of the present study was to identify region-specific expression of lncRNAs in patients with AF and to define the functional role of lncRNA in H9C2 cells.

\section{Materials and methods}

Patients. The Medical Ethics Committee of the First Affiliated Hospital of Harbin Medical University (Harbin, China) 
approved the experiments of the present study, and all patients gave their informed consent prior to the study. The current study included paired LA-PV and LAA samples from 16 patients with persistent AF undergoing cardiac surgery. The LA-PV samples were used as the experimental group and the LAA samples were used as the control group. All patients had a history of AF $>6$ months prior to surgery. AF was diagnosed by evaluation of medical records and 12-lead electrocardiogram observations.

Microarray analysis. Total RNAs were isolated from atrial samples in the experimental and control groups using TRIzol reagent (Invitrogen; Thermo Fisher Scientific, Inc., Waltham, MA, USA) according to manufacturer's protocol. The mRNAs were purified from total RNA subsequent to removal of rRNA (mRNA-Only Eukaryotic mRNA Isolation kit; Epicenter; Illumina, Inc., San Diego, CA, USA). Each sample was then and transcribed into cRNA along the entire length of the transcripts without 3' bias using a SuperScript Double-Strand Synthesis kit (Invitrogen; Thermo Fisher Scientific, Inc.). The cDNAs were labeled with Cy3 using Quick-Ampl labeling kit (Agilent Technologies, Inc., Santa Clara, CA, USA). Labeled miRNAs were hybrided to the human microarray chip (Human LncRNA Microarray V2.0). Hybridization signals were detected using an Agilent scanner. Images were quantified using the Agilent Feature Extract software, version 11.0 (Agilent Technologies, Inc.). Differential expression of IncRNA between the experimental and control groups was identified by volcano plot. The lncRNAs with $\geq 2$ fold changes between the experimental and control groups were selected.

Analysis of the association of lncRNAs with target mRNAs. Pearson correlation analysis was used to determine the association of the IncRNA AK055347 with direct regulated expression of target mRNAs. mRNAs with high Pearson's correlation coefficients $(>0.75)$ were selected as the targets of lncRNA AK055347.

Cell culture. H9C2 cells, a clonal cell line of cardiomyocytes derived from embryonic rat heart tissues, were obtained from the American Type Culture Collection (Manassas, VA, USA). Cells were cultured in Dulbecco's modified Eagle's medium (Invitrogen; Thermo Fisher Scientific, Inc.) containing 10\% fetal bovine serum (HyClone; GE Healthcare Life Sciences, Logan, UT, USA), $100 \mathrm{U} / \mathrm{ml}$ penicillin and $100 \mathrm{mg} / \mathrm{ml}$ streptomycin. The cells were maintained in a humidified atmosphere with $5 \% \mathrm{CO}_{2}$ at $37^{\circ} \mathrm{C}$. Cells were subcultured at 1:3 ratio every 3 days.

Small interfering RNA (siRNA). The rat cDNA sequence was analyzed for potential siRNA target sequences. Three oligonucleotides were analyzed for the inhibition of the expression of AK055347. The siRNAs tested were as follows: siRNA \#1, 5'-gaggaucuac uguuaacaga-3' (sense) and 5'-cuccuagaugac aauuguucu-3' (antisense); siRNA \#2, 5'-cauaccaccaagccu ucuu-3' (sense) and 5'-guauggugguucggaagaa-3' (antisense); siRNA \#3, 5'-cguguccucucugcugucucc-3' and 5'-gcacaggagacg acagagg-3'. H9C2 cells were transfected with siRNAs using Lipofectamine 2000.
Cell viability. Cell viability was analyzed using the Cell Counting Kit 8 (CCK-8) assay (Dojindo Molecular Technologies, Inc., Shanghai, China). Cells were seeded into a 96-well plate at a density of $10^{4}$ cells/well. Cells were transfected with siRNAs and cultured in $5 \% \mathrm{CO}_{2}$ at $37^{\circ} \mathrm{C}$ for $48 \mathrm{~h}$. CCK- 8 solution $(10 \mu \mathrm{l})$ was added to each well and cultured for an additional $2 \mathrm{~h}$. Absorbance was measured at $490 \mathrm{~nm}$ using a MultiSkan 3 microplate reader (Thermo Fisher Scientific, Inc.).

Reverse transcription-quantitative polymerase chain reaction $(R T-q P C R)$. Total RNA was isolated from $\mathrm{H} 9 \mathrm{C} 2$ cells using TRIzol reagent (Invitrogen; Thermo Fisher Scientific, Inc.) according to the manufacturer's protocol. RNA was reverse transcribed into cDNA using the reverse transcriptase of Moloney murine leukemia virus (Promega Corporation, Madison, WI, USA). RT-qPCR was performed in a final volume of $20 \mu \mathrm{l}$ containing $2 \mu \mathrm{l}$ cDNA, $1 \mu \mathrm{l}$ of each primer, and $10 \mu \mathrm{l}$ SYBR Green (Applied Biosystems; Thermo Fisher Scientific, Inc.). Primers used for amplification of AK055347 were 5'-AАCTCCTAACACATCTCT-3' (sense) and 5'-CTA AGGTAGTCAGTCTCA-3' (antisense). U6 was used as a housekeeping gene. The reaction conditions were as follows: $95^{\circ} \mathrm{C}$ for $10 \mathrm{~min} ; 95^{\circ} \mathrm{C}$ for $15 \mathrm{sec}, 55^{\circ} \mathrm{C}$ for $1 \mathrm{~min}$ with 40 cycles. Melting curve analyses were performed to verify the amplification specificity. The gene expression $\Delta \mathrm{Cq}$ values of AK055347 from each sample were calculated by normalizing with internal control U6. The relative expression of AK055347 was calculated using $2^{-\Delta \Delta C q}$ method (24).

Western blotting. H9C2 cells were homogenized on ice in lysis buffer. Lysates were centrifuged at $13,000 \mathrm{x} g$ at $4^{\circ} \mathrm{C}$ for $20 \mathrm{~min}$. The supernatants were collected and protein concentrations were determined using a Bicinchoninic Acid Protein Quantitation kit (Abcam, Cambridge, MA, USA). Proteins were resolved using 10-12\% SDS-PAGE, and transferred onto polyvinylidene fluoride membranes by electroblotting. Membranes were incubated with primary antibodies against Cyp450 (ab196836; rabbit anti-rat; monoclonal; 1:100; Abcam), adenosine triphosphate (ATP) synthase (ab54880; mouse anti-rat; monoclonal; 1:100; Abcam) and MSS51 (ab63801; mouse anti-rat; monoclonal; 1:100; Abcam). The antibodies were incubated at $4^{\circ} \mathrm{C}$ overnight. GAPDH (cat. no. BM1623; Wuhan Boster Biological Technology, Ltd., Wuhan, China) was used as a loading control. Membranes were then incubated with horseradish peroxidase-conjugated goat anti-mouse (cat. no. ab6789) or anti-rabbit (cat. no. ab6721) secondary antibodies (1:10,000; Abcam) at room temperature for $40 \mathrm{~min}$. Bands were visualized by exposure to X-ray film (Kodak, Rochester, NY, USA). Images were acquired by scanning the films, and band gray values were analyzed using ImageJ software (National Institutes of Health, Bethesda, MD, USA; http://rsb.info.nih.gov/ij/index.html).

Immunofluorescence staining. $\mathrm{H} 9 \mathrm{C} 2$ cells were grown on glass coverslips in sterile 6-well plates until confluence was reached. Cells were then rinsed with phosphate-buffered saline (PBS) three times, and fixed in $4 \%$ paraformaldehyde for $15 \mathrm{~min}$ at room temperature. The cells were then permeabilized with $0.5 \%$ Triton X-100 for $20 \mathrm{~min}$. Subsequent to three washes with 


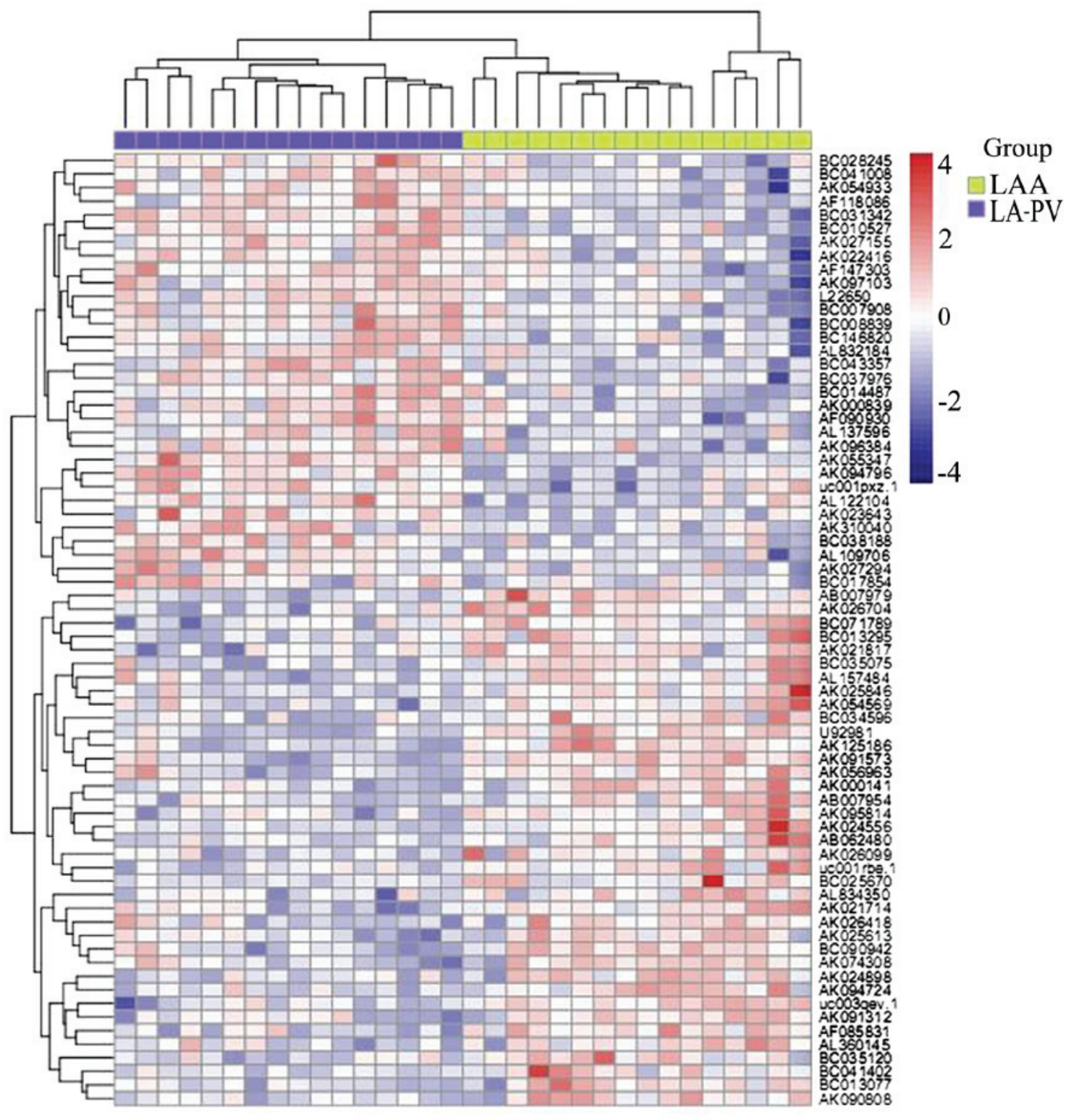

Figure 1. Microarray analysis of the long non-coding RNA expression profile between the LA-PV and LAA in patients with AF. LA-PV, pulmonary vein and the surrounding left atrial area; LAA, left atrial appendage; $\mathrm{AF}$, atrial fibrillation.

PBS, cells were incubated with primary antibodies against MSS51 (ab165144; mouse anti-rat; polyclonal; 1:100; Abcam) at $4^{\circ} \mathrm{C}$ overnight. PBS without primary antibodies was used as a negative control. After the primary antibody was removed by washing in PBS, immunoreactivity was detected by incubation in fluorescein isothiocyanate-coupled secondary antibodies (goat anti-mouse IgG; 1:100; cat. no. ab6785; Abcam) at room temperature for $1 \mathrm{~h}$. Cells were counterstained with DAPI. Following washing of the coverslips with PBS, the cells were examined and photographed with a fluorescence microscope (Olympus Corporation, Tokyo, Japan).

Statistical analysis. Analyses were performed using SPSS software, version 13.0 (SPSS, Inc., Chicago, IL, USA). All values are presented as the mean \pm standard deviation. One-way analysis of variance followed by Bonferroni's test was used to compare the differences. $\mathrm{P}<0.05$ was considered to indicate a statistically significant difference.

\section{Results}

lncRNAs are abnormally expressed in patients with $A F$. In order to investigate the role of lncRNAs in AF, microarray-based profiling analysis was conducted using LA-PV and LAA tissue samples in patients with AF. By comparing the expression profiles between LA-PV and LAA tissue samples, 94 lncRNAs were identifed that were either significantly upregulated or downregulated ( $>2$ fold change) in LA-PV samples compared with LAA samples (Fig. 1). Table I presents the top 10 lncRNAs including AK055347, AK310040, AK026494, BC010527, AK027294, AB007979, AK091573, UC003qev.1, AK125186 and U9981. AK055347 was selected for further analysis.

Knockdown of lncRNA AK055347 inhibited cell viability in H9C2 cells. The role of lncRNA AK055347 in cell viability in $\mathrm{H} 9 \mathrm{C} 2$ cells was investigated using siRNA to knockdown 
Table I. The expression levels of the top ten lncRNAs with the most significant changes between LA-PV and LAA tissues.

\begin{tabular}{lccc}
\hline lncRNAs & LAA & LA-PV & P-values \\
\hline AK055347 & 5.178 & 6.565 & $<0.00001$ \\
AK310040 & 3.736 & 4.823 & 0.0006 \\
AK026494 & 6.273 & 7.159 & 0.004 \\
BC010527 & 5.309 & 6.156 & $<0.0001$ \\
AK027294 & 5.708 & 6.515 & 0.00187 \\
AB007979 & 4.898 & 3.710 & $<0.0001$ \\
AK091573 & 6.428 & 5.196 & $<0.0001$ \\
UC003qev.1 & 9.524 & 8.210 & $<0.0001$ \\
AK125186 & 6.391 & 4.969 & $<0.0001$ \\
U9981 & 8.788 & 7.069 & $<0.0001$ \\
\hline
\end{tabular}

lncRNAs, long non-coding RNAs; LA-PV, pulmonary vein and the surrounding left atrial area; LAA, left atrial appendage.

Table II. The proteins that are targets of AK055347 predicted by Pearson correlation analysis.

\begin{tabular}{ll}
\hline Proteins & AK055347 \\
\hline FAM78B & 0.991284 \\
MSS51 & 0.916019 \\
PPM1E & 0.886859 \\
CCDC19 & 0.865633 \\
AKR1B10 & 0.850339 \\
OSBPL6 & 0.823617 \\
GALNTL5 & 0.80761 \\
CENPN & 0.778999 \\
NUP62CL & 0.775631 \\
BOD1L2 & 0.766192 \\
\hline
\end{tabular}

lncRNA AK055347. RT-qPCR results demonstrated that siRNA\#1, \#2 and \#3 significantly downregulated AK055347 expression in H9C2 cells (Fig. 2A). Knockdown of AK055347 significantly reduced cell viability of H9C2 cells (Fig. 2B).

Knockdown of IncRNA AK055347 inhibited the expression of Cyp450 and ATP synthase in H9C2 cells. The protein expression of Cyp450 and ATP synthase was measured in H9C2 cells treated with siRNAs against AK055347. Western blotting indicated that knockdown of AK055347 inhibited the expression of Cyp450 and ATP synthases in H9C2 cells (Fig. 3).

Knockdown of lncRNA AK055347 inhibited the metabolism-associated protein MSS51 in H9C2 cells. Microarray analysis indicated that MSS51 protein was associated with the expression of the lncRNA AK055347 (Table II). It was further investigated whether IncRNA AK055347 regulated the expression of the metabolism-associated protein MSS51 in H9C2 cells treated with siRNAs against lncRNA AK055347, using immunofluorescence and western blotting.
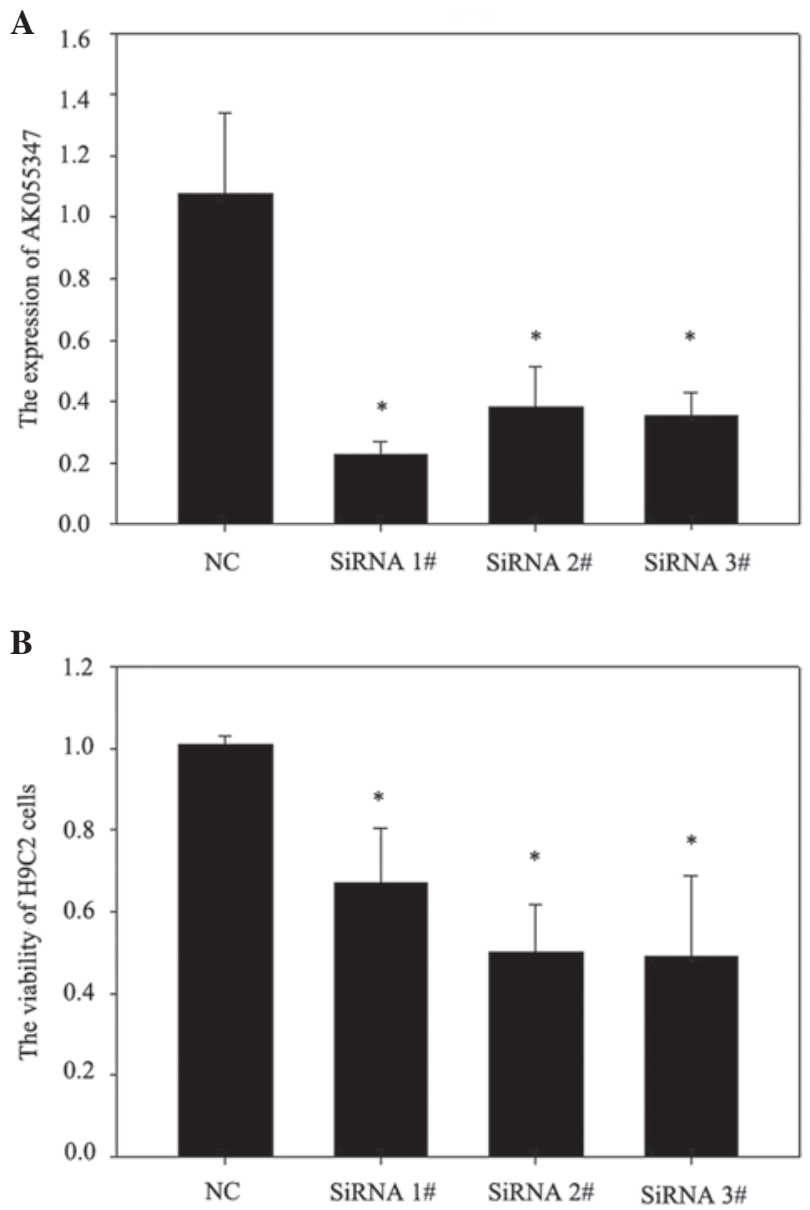

Figure 2. Knockdown of AK055347 inhibited cell viability in H9C2 cells (A) The expression of AK055347 in H9C2 cells treated with NC, siRNA\#1, siRNA\#2 and siRNA\#3 against AK055347. (B) The viability of $\mathrm{H} 9 \mathrm{C} 2$ cells treated with NC, siRNA\#1, siRNA\#2 and siRNA\#3 against AK055347. ${ }^{*} \mathrm{P}<0.05$ vs. NC. NC, negative control; siRNA, small interfering RNA.

Immunofluorescence staining indicated that knockdown of AK055347 reduced the expression of MSS51 in H9C2 cells (Fig. 4A). Consistent with immunofluorescence results, western blotting results indicated that knockdown of AK055347 inhibited the expression of MSS51 in H9C2 cells (Fig. 4B).

\section{Discussion}

Increasing evidence has demonstrated that lncRNAs serve an important role in the control of the gene regulatory network via transcriptional and post-transcriptional regulation and epigenetic targeting $(25,26)$. The tissue-specific gene expression programs are finely controlled during heart development (27). Previously, lncRNAs have been demonstrated to be important for cardiac lineage commitment and heart development $(28,29)$. The important role of lncRNAs in the heart is further supported by several studies indicating that lncRNAs are associated with numerous cardiac diseases including myocardial infarction (15), heart failure (16) and left ventricular hypertrophy (17). However, it remains unclear whether lncRNAs are involved in AF. In the present study, microarray analysis was used to investigate the IncRNA expression profiles between two left atrial regions, LA-PV and LAA in patients 


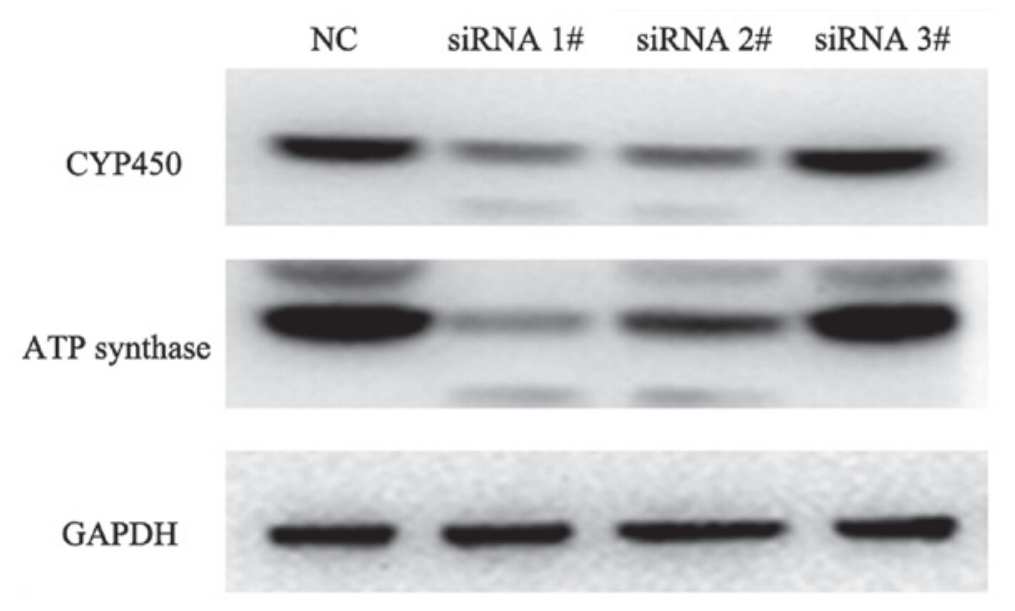

Figure 3. Representative western blot showing the expression of Cyp450 and ATP synthase in H9C2 cells treated with NC, siRNA\#1, siRNA\#2 and siRNA\#3 against AK055347. ATP, adenosine triphosphate; NC, negative control; siRNA, small interferring RNA.

A

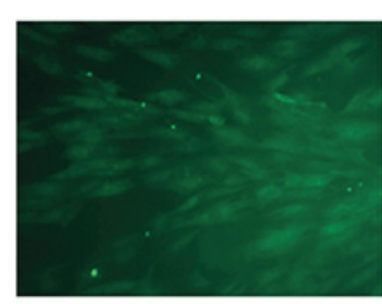

NC

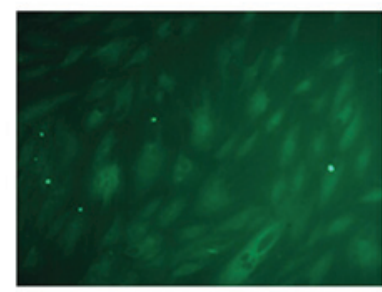

siRNA 2\#

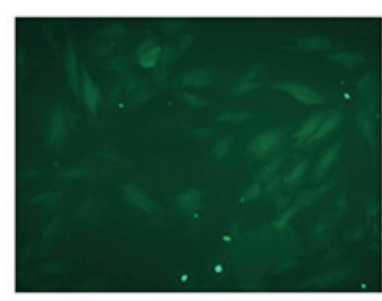

siRNA 1\#

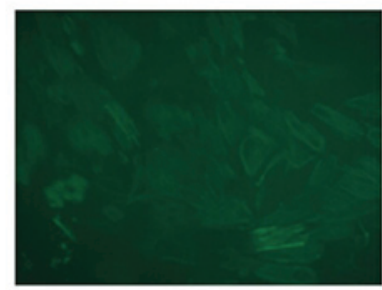

siRNA 3\#

B NC SiRNA 1\# siRNA2\# siRNA3\#

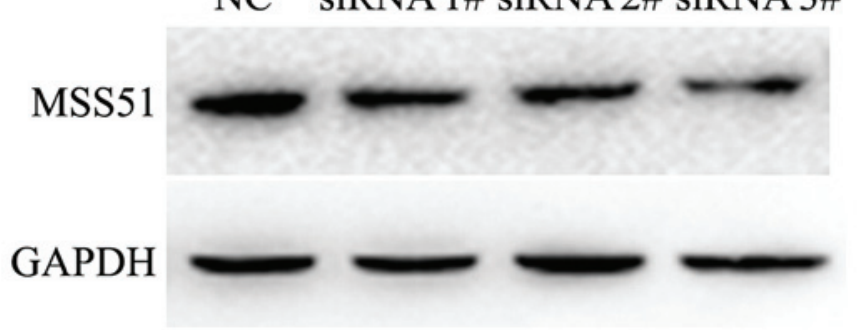

Figure 4. Knockdown of AK055347 inhibited MSS51 in H9C2 cells. (A) Representative immunofluorescence staining for MSS51 in H9C2 cells treated with NC, siRNA\#1, siRNA\#2 and siRNA\#3 against AK055347. (B) Representative western blot showing the expression of MSS51 in H9C2 cells treated with NC, siRNA\#1, siRNA\#2 and siRNA\#3 against AK055347. NC, negative control; siRNA, small interfering RNA.

with AF. A total of 94 lncRNAs were identified to be differentially expressed between the LA-PV and LAA in patients with AP. AK055347 was one of lncRNAs with the most significant alterations, thus the function of A055347 in H9C2 cardiomyocytes was assessed using siRNA to knock down AK055347. Knockdown of AK055347 inhibited cell viability of H9C2 cells, accompanied by downregulation of Cyp450 and ATP synthases. Furthermore, microarray analysis identified that MSS51 was a target of AK055347. The microarray result was confirmed by immunofluorescence and western blot analysis results indicating knockdown of AK055347 inhibited the expression of MSS51 in H9C2 cells. The results of the current 
study suggest that the lncRNA AK055347 may contribute to the pathogenesis of AF.

It has been reported that LA-PV is an important region for AF (30). Yeh et al (8) reported that 391 genes were differentially expression between the LA-PV and LAA in patients with persistent AF, including genes associated with arrhythmia, cell death, inflammation and hypertrophy. Similarly, it was identified that IncRNAs also exhibited this region-specific expression between LA-PV and LAA. A total of 94 lncRNAs that were differentially expressed between the two regions were identified. In addition, it was observed that knockdown of AK055347 inhibited cell viability in H9C2 cells, suggesting that AK055347 may be associated with cell survival in cardiomyocytes.

Previous studies have demonstrated that $\mathrm{AF}$ is associated with energy synthesis or consumption (20-22). Mitochondria produce energy via the process of oxidative phosphorylation, and mitochondrial dysfunction has been identified to be associated with AF $(31,32)$. It has been reported that mitochondrial ATP synthase is upregulated in an animal model of AF (19). In the present study, it was demonstrated that lncRNA AK055347 was upregulated in the LA-PV in patients with AF, and knockdown of AK055347 significantly downregulated the expression of ATP synthase in H9C2 cells, suggesting that AK055347 may regulate mitochondrial energy production during AF. This hypothesis was further supported by the observations that knockdown of AK055347 reduced the expression of Cyp450, the terminal oxidase enzymes in electron transfer chain.

MSS51 is a specific mitochondrial cytochrome $c$ oxidase (COX) regulator that is important for COX1 assembly $(33,34)$. It has been reported that MSS51 promotes COX1 translation via interaction with the 5'-UTR of COX1 and inhibits translation via interaction with newly synthesized COX1 $(35,36)$. This dual effect of MSS51 is important for correct assembly of COX in the respiratory complex (37). In the present study, microarray analysis demonstrated that MSS51 was the target of lncRNA AK055347. Furthermore, the expression of MSS51 was significantly downregulated in H9C2 cells subsequent to knockdown of AK055347. The current study suggests that AK055347 may regulate COX1 assembly via targeting its regulator MSS51.

In summary, a total of 94 lncRNAs were identified that were differentially expressed between the LA-PV and LAA in patients with AP. In addition, it was demonstrated that AK055347 was important for cell survival, due to the fact that knockdown of AK055347 significantly inhibited viability of H9C2 cells. Furthermore, knockdown of A055347 inhibited the expression of mitochondrial Cyp450, ATP synthase, and MSS51, suggesting that AK055347 may inhibit mitochondrial energy production. The present study suggests that lncRNAs may contribute to AF pathogenesis, and the lncRNA AK055347 may regulate mitochondrial energy production via regulation of Cyp450, ATP synthase and MSS51.

\section{Acknowledgements}

The current study was supported by grants from the Heilongjiang Province Natural Science Foundation of China (grant no. H201443) and the First Affiliated Hospital of Harbin Medical University.

\section{References}

1. Gialdini G, Nearing K, Bhave PD, Bonuccelli U, Iadecola C, Healey JS and Kamel H: Perioperative atrial fibrillation and the long-term risk of ischemic stroke. JAMA 312: 616-622, 2014.

2. Healey JS and Connolly SJ: Atrial fibrillation: Hypertension as a causative agent, risk factor for complications, and potential therapeutic target. Am J Cardiol 91: 9G-14G, 2003.

3. Oluleye OW, Rector TS, Win S, McMurray JJ, Zile MR, Komajda M, McKelvie RS, Massie B, Carson PE and Anand IS: History of atrial fibrillation as a risk factor in patients with heart failure and preserved ejection fraction. Circ Heart Fail 7: 960-966, 2014

4. Kannel WB, Wolf PA, Benjamin EJ and Levy D: Prevalence, incidence, prognosis, and predisposing conditions for atrial fibrillation: Population-based estimates. Am J Cardiol 82: 2N-9N, 1998.

5. Nattel S: New ideas about atrial fibrillation 50 years on. Nature 415: 219-226, 2002.

6. Zöller B, Ohlsson H, Sundquist J and Sundquist K: High familial risk of atrial fibrillation/atrial flutter in multiplex families: A nationwide family study in Sweden. J Am Heart Assoc 2: $\mathrm{e} 003384,2013$

7. Ou F, Rao N, Jiang X, Qian M, Feng W, Yin L and Chen X: Analysis on differential gene expression data for prediction of new biological features in permanent atrial fibrillation. PLoS One 8: e76166, 2013

8. Yeh YH, Kuo CT, Lee YS, Lin YM, Nattel S, Tsai FC and Chen WJ: Region-specific gene expression profiles in the left atria of patients with valvular atrial fibrillation. Heart Rhythm 10: 383-391, 2013.

9. Goodrich JA and Kugel JF: Non-coding-RNA regulators of RNA polymerase II transcription. Nat Rev Mol Cell Biol 7: 612-616, 2006.

10. Yu FJ, Zheng JJ, Dong PH and Fan XM: Long non-coding RNAs and hepatocellular carcinoma. Mol Clin Oncol 3: 13-17, 2015

11. Sun M and Kraus WL: Minireview: Long noncoding RNAs: New 'links' between gene expression and cellular outcomes in endocrinology. Mol Endocrinol 27: 1390-1402, 2013.

12. Quagliata L and Terracciano LM: Liver diseases and long non-coding RNAs: New insight and perspective. Front Med (Lausanne) 1: 35, 2014.

13. Li J, Xuan Z and Liu C: Long non-coding RNAs and complex human diseases. Int J Mol Sci 14: 18790-18808, 2013.

14. Scheuermann JC and Boyer LA: Getting to the heart of the matter: Long non-coding RNAs in cardiac development and disease. EMBO J 32: 1805-1816, 2013

15. Ishii N, Ozaki K, Sato H, Mizuno H, Saito S, Takahashi A, Miyamoto Y, Ikegawa S, Kamatani N, Hori M, et al: Identification of a novel non-coding RNA, MIAT, that confers risk of myocardial infarction. J Hum Genet 51: 1087-1099, 2006.

16. Di Salvo TG, Guo Y, Su YR, Clark T, Brittain E, Absi T, Maltais S and Hemnes A: Right ventricular long noncoding RNA expression in human heart failure. Pulm Circ 5: 135-161, 2015.

17. Zhang L, Hamad EA, Vausort M, Funakoshi H, Feldman AM, Wagner DR and Devaux Y: Identification of candidate long noncoding RNAs associated with left ventricular hypertrophy. Clin Transl Sci 8: 100-106, 2015.

18. Ausma J, Coumans WA, Duimel H, Van der Vusse GJ, Allessie MA and Borgers M: Atrial high energy phosphate content and mitochondrial enzyme activity during chronic atrial fibrillation. Cardiovasc Res 47: 788-796, 2000.

19. Barbey O, Pierre S, Duran MJ, Sennoune S, Lévy S and Maixent JM: Specific up-regulation of mitochondrial F0F1-ATPase activity after short episodes of atrial fibrillation in sheep. J Cardiovasc Electrophysiol 11: 432-438, 2000.

20. Tsuboi M, Hisatome I, Morisaki T, Tanaka M, Tomikura Y, Takeda S, Shimoyama M, Ohtahara A, Ogino K, Igawa O, et al: Mitochondrial DNA deletion associated with the reduction of adenine nucleotides in human atrium and atrial fibrillation. Eur J Clin Invest 31: 489-496, 2001.

21. Cha YM, Dzeja PP, Shen WK, Jahangir A, Hart CY, Terzic A and Redfield MM: Failing atrial myocardium: Energetic deficits accompany structural remodeling and electrical instability. Am J Physiol Heart Circ Physiol 284: H1313-H1320, 2003. 
22. Seppet E, Eimre M, Peet N, Paju K, Orlova E, Ress M, Kõvask S, Piirsoo A, Saks VA, Gellerich FN, et al: Compartmentation of energy metabolism in atrial myocardium of patients undergoing cardiac surgery. Mol Cell Biochem 270: 49-61, 2005.

23. Zhang J, Cui X, Shen Y, Pang L, Zhang A, Fu Z, Chen J, Guo X, Gan W and Ji C: Distinct expression profiles of LncRNAs between brown adipose tissue and skeletal muscle. Biochem Biophys Res Commun 443: 1028-1034, 2014.

24. Livak KJ and Schmittgen TD: Analysis of relative gene expression data using real-time quantitative PCR and the 2(-Delta Delta C(T)) method. Methods 25: 402-408, 2001.

25. Rinn JL and Chang HY: Genome regulation by long noncoding RNAs. Annu Rev Biochem 81: 145-166, 2012.

26. Ounzain S, Crippa S and Pedrazzini T: Small and long non-coding RNAs in cardiac homeostasis and regeneration. Biochim Biophys Acta 1833: 923-933, 2013.

27. Bruneau BG: Signaling and transcriptional networks in heart development and regeneration. Cold Spring Harb Perspect Biol 5: a008292, 2013

28. Grote P, Wittler L, Hendrix D, Koch F, Währisch S, Beisaw A, Macura K, Bläss G, Kellis M, Werber M and Herrmann BG: The tissue-specific lncRNA Fendrr is an essential regulator of heart and body wall development in the mouse. Dev Cell 24: 206-214, 2013.

29. Klattenhoff CA, Scheuermann JC, Surface LE, Bradley RK, Fields PA, Steinhauser ML, Ding H, Butty VL, Torrey L, Haas S, et al: Braveheart, a long noncoding RNA required for cardiovascular lineage commitment. Cell 152: 570-583, 2013.

30. Kabra R and Singh JP: Catheter ablation targeting complex fractionated atrial electrograms for the control of atrial fibrillation. Curr Opin Cardiol 27: 49-54, 2012.
31. Montaigne D, Marechal X, Lefebvre P, Modine T, Fayad G, Dehondt H, Hurt C, Coisne A, Koussa M, Remy-Jouet I, et al: Mitochondrial dysfunction as an arrhythmogenic substrate: A translational proof-of-concept study in patients with metabolic syndrome in whom post-operative atrial fibrillation develops. J Am Coll Cardiol 62: 1466-1473, 2013

32. Slagsvold KH, Johnsen AB, Rognmo O, Høydal MA, Wisløff U and Wahba A: Mitochondrial respiration and microRNA expression in right and left atrium of patients with atrial fibrillation. Physiol Genomics 46: 505-511, 2014.

33. Fontanesi F, Clemente $\mathrm{P}$ and Barrientos A: Cox 25 teams up with Mss51, Ssc1, and Cox14 to regulate mitochondrial cytochrome $c$ oxidase subunit 1 expression and assembly in Saccharomyces cerevisiae. J Biol Chem 286: 555-566, 2011.

34. Pierrel F, Bestwick ML, Cobine PA, Khalimonchuk O, Cricco JA and Winge DR: Coal links the Mss51 post-translational function to Cox 1 cofactor insertion in cytochrome $c$ oxidase assembly. EMBO J 26: 4335-4346, 2007.

35. Perez-Martinez X, Broadley SA and Fox TD: Mss51p promotes mitochondrial Cox1p synthesis and interacts with newly synthesized Cox1p. EMBO J 22: 5951-5961, 2003.

36. Barrientos A, Zambrano A and Tzagoloff A: Mss51p and Cox 14p jointly regulate mitochondrial Cox1p expression in Saccharomyces cerevisiae. EMBO J 23: 3472-3482, 2004.

37. Perez-Martinez X, Butler CA, Shingu-Vazquez M and Fox TD Dual functions of Mss51 couple synthesis of Cox1 to assembly of cytochrome $c$ oxidase in Saccharomyces cerevisiae mitochondria. Mol Biol Cell 20: 4371-4380, 2009. 